\title{
Evaluation of Relations between Extreme Precipitation and Temperature in Observational Time Series from the Czech Republic
}

\author{
Marta Martinkova ${ }^{1}$ and Martin Hanel ${ }^{1,2}$ \\ ${ }^{1}$ Faculty of Environmental Sciences, Czech University of Life Sciences Prague, Kamycka 129, Suchdol, 16521 Praha 6, Czech Republic \\ ${ }^{2}$ T. G. Masaryk Water Research Institute, Podbabska 30, 16000 Praha 6, Czech Republic
}

Correspondence should be addressed to Marta Martinkova; martinkovam@fzp.czu.cz

Received 26 February 2016; Revised 18 May 2016; Accepted 6 June 2016

Academic Editor: Ji Chen

Copyright (c) 2016 M. Martinkova and M. Hanel. This is an open access article distributed under the Creative Commons Attribution License, which permits unrestricted use, distribution, and reproduction in any medium, provided the original work is properly cited.

\begin{abstract}
The intensity of precipitation extremes is expected to increase as the climate warms and it may cause floods and increase erosion. From the Clausius-Clapeyron relation (CC) it follows that the maximum moisture content of the atmosphere increases by approximately $7 \%$ per degree as temperature rises. However, the increases in observed hourly precipitation extremes of approximately two times the CC relation were described recently. This super CC scaling is attributed to the increased prevalence of convective rainfall and decreased prevalence of stratiform rainfall as temperatures increase. We carried out the disaggregation of precipitation into prevailing stratiform and convective component on the observational data from the Czech Republic for 19662006. Then, we analyzed trends in characteristics of disaggregated events and assessed correlation of precipitation intensities with daily mean temperature. The results suggest the increasing trend of convective precipitation in summer. The scaling for total rain events is steeper than for the events with prevailing convective component and for the events with prevailing stratiform component. It is a result of mixing of the two storm types. At higher temperature the events with prevailing convective component prevail and vice versa.
\end{abstract}

\section{Introduction}

As the climate warms, floods are expected to occur more often and to be more extreme due to more extreme precipitation [1]. The observed hydrological extremes are in line with this expectation, for example, [2-4], and recent observed trends in precipitation (see, e.g., $[5,6]$ ) are consistent with future regional climate projections [7].

One of the explanations is that the warmer air is capable of holding more moisture since the maximum moisture content of the atmosphere increases with approximately 7\% per degree of Celsius (Clausius-Clapeyron relation, CC). Thus, the positive changes in the volume of individual rain events and precipitation intensity are driven by increasing temperature [8]. As there is agreement between observed and projected increase in temperature [9], more floods connected with convective rains especially in summer can be expected.
Interestingly, the increases in observed hourly precipitation extremes of approximately two times the CC relation have been described recently $[8,10,11]$. This so-called super CC scaling is attributed to an increased prevalence of convective rainfall and decreased prevalence of stratiform rainfall as temperatures increases. Therefore, the super CC behaviour emerges only as a consequence of simultaneous $\mathrm{CC}$ behaviour of both stratiform and convective precipitation in such temperature regime where the two types coexist [12]. However, a super CC rate of convective precipitation has not been explained yet [13]. Increased prevalence of convective rainfall was demonstrated on a large dataset from Germany and explained by its higher sensitivity to increases in air temperature [14].

Various methods for identification of stratiform and convective precipitation have been developed. These methods are usually based on synoptic and radar observations, state of 
weather, rain intensity fluctuations, or lightning occurrence $[15,16]$.

The stratiform and convective components of precipitation can be distinguished directly in precipitation data [17]. The approach is based on the observation that relation between cumulative precipitation and precipitation intensity is nearly exponential. This approach and the derived method have been used successfully for the Spanish Mediterranean coast [18].

The aim of the presented study is to analyze the scaling slopes between extreme precipitation and air temperature in the Czech Republic. We use the methodology based on studies of Tremblay [17] and Ruiz-Leo et al. [18] for distinguishing between rain events with prevailing convective component and with prevailing stratiform component. Subsequently, we use the temperature binning method for scaling analysis [19, 20]. We performed the analysis separately for two regions in the Czech Republic: western (more influenced by oceanic climate) and eastern (more influenced by continental climate).

We address the following research questions:

(1) Is the methodology of the threshold precipitation rate [18] applicable for conditions influenced by continental climate?

(2) Are there any trends in precipitation above and below the threshold precipitation rate?

(3) Can super CC scaling described in previous studies be identified in observational data from the Czech Republic?

(4) Is the scaling influenced by storm origin (convective/stratiform)?

The paper is organized as follows: the data, study area, and methods are presented in Section 2. The obtained results and their implications are presented and discussed in Section 3. The paper ends with conclusions in Section 4.

\section{Data and Methods}

2.1. Study Area. Precipitation patterns are heterogeneous over the Czech Republic $\left(78866 \mathrm{~km}^{2}\right)$. The reasons are combined Atlantic, Mediterranean, and continental influences along with the rather complex orography. The western part of the Czech Republic is distinctively influenced by the inflow of mist maritime air from north Atlantic. On the other hand, the eastern part is affected more by inflow of warm, moist air from Mediterranean. The most of annual total precipitation falls in the warm half of the year (April-September).

In summer, the convective precipitation slightly predominate over the stratiform. In spring, large scale stratiform precipitation prevails and it dominates in autumn and winter. Subdaily precipitation extremes are generally connected to convective events in the warm half of the year [16].

There is strong evidence of increased floods in the Czech Republic. The large floods occurred in 1997 (the Odra basin), in 2002 (the Elbe basin), and in 2013 (the Elbe basin). In August 2010, the heavy precipitation in northern Bohemia caused the extensive flooding [21]. Flash floods from extreme convective precipitation occurred, for example, in 1998 in
TABLE 1: Overview of the stations used for analysis.

\begin{tabular}{lccc}
\hline ID & Name & Altitude $[\mathrm{m}]$ & Region \\
\hline B1STRN01 & Strání & 383 & Eastern \\
B1VIZO01 & Vizovice & 313 & Eastern \\
B2BTUR01 & Brno & 241 & Eastern \\
B2KMYS01 & Kostelní Myslová & 569 & Eastern \\
B2VMEZ01 & Velké Meziříćí & 452 & Eastern \\
C1CHUR01 & Churáňov & 1118 & Western \\
C2TABO01 & Tábor & 459 & Western \\
C2VBRO01 & Vyšší Brod & 559 & Western \\
H3HRAD01 & Hradec Kralové & 278 & Western \\
H3SVRA01 & Svratouch & 737 & Eastern \\
L2PRIM01 & Přimda & 742 & Western \\
L3CHEB01 & Cheb & 483 & Western \\
O1CERV01 & Červená & 749 & Eastern \\
O1LUCI01 & Lučina & 300 & Eastern \\
U1DOKS01 & Doksany & 158 & Western \\
U2DOKY01 & Doksy & 284 & Western \\
U2VARN01 & Varnsdorf & 365 & Western \\
\hline
\end{tabular}

Orlické hory mountains and in 2009 in several regions of the country.

While studying the trends in precipitation, it is suitable to assess the potential oscillations detected in the data. Noticeable multidecadal oscillatory behaviour of precipitation extremes was detected by study using daily data for a large number of stations across Europe for central-western Europe. The recent upward trend in extreme precipitation is partly related to positive phase of the oscillation [22]. Similar behaviour was observed for the station in southern Bohemia (C2TABO01; see Figure 1 for the location of the station) [23].

2.2. Data. Time series of 30 -minute precipitation data were provided by the Czech Hydrometeorological Institute. Data from 17 stations covering a period from 1961 to 2011 are examined here (Table 1, Figure 1). The time series are divided into two groups according the division into the western and eastern regions. The data are in general available for mid-May to mid-September only because the noticeable amount of precipitation falls as snow in winter. However, this is not an issue here since we focus on scaling of precipitation extremes with air temperature [15]. The stations were selected mainly based on the data availability and spatial coverage of the Czech Republic territory. The data at each station originate from two sources: digitized pluviograph records and tipping bucket records. For years without reliable data, the data from the closest station at a comparable elevation were used. The preprocessing of the station data is described in detail in [23]. In the present paper, the original $30 \mathrm{~min}$ data have been aggregated to $6 \mathrm{~h}$ resolution in order to be consistent with previous relevant studies $[6,18]$ and because the $6 \mathrm{~h}$ is the usual minimal time for formation of a convective event [18]. Daily data on mean temperature for each station were obtained from E-OBS gridded dataset [24]. 


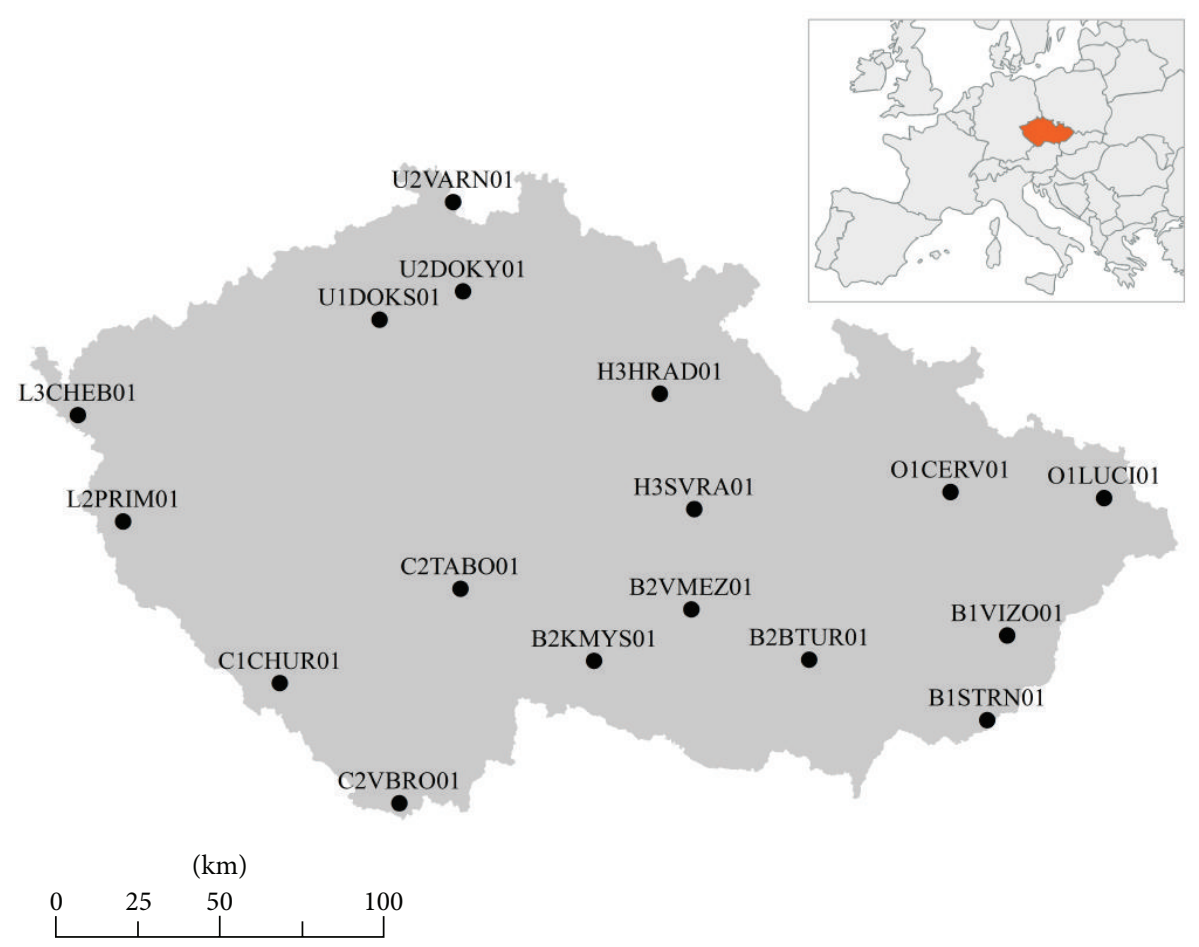

FIGURE 1: The location of stations used for the analysis.

2.3. Identification of Threshold Precipitation Rate. It is possible to observe exponential distribution while the relation between cumulative precipitation $(P$, in $\mathrm{mm})$ and precipitation rate is represented ( $R$, in $\mathrm{mm}$ per time unit) [17]. In this study, the disaggregation of precipitation into prevailing stratiform and convective component is based on this observation. The function can be divided into two terms:

$$
P(R)=A(t) e^{-B(t) \cdot R}+p^{\prime \prime} .
$$

Parameters $A$ and $B$ are constant. They are to be determined for each period $(t) . P(R)$ is the total cumulative precipitation for a given intensity $R$ and $p^{\prime \prime}$ are fluctuations over the exponential function. The exponential term in (1) can be associated with the stratiform component of precipitation and the second term, $p^{\prime \prime}$, is related to the convective component. Then, (1) can be rewritten as

$$
P(R)=P_{s}+P_{c} \text {. }
$$

The precipitation intensity $R$ is obtained by dividing cumulative precipitation during a period of time $\Delta t$ by the period of time:

$$
R(t)=\frac{P(t)}{\Delta t}
$$

Six-hour precipitation data (4 values per day) are aggregated into precipitation rate bins. In line with [17] a $2 \mathrm{~mm}$ bin width was used. Only occasionally when the determined threshold precipitation rate (THR, see later) was of infinite value, the first closest bin width with realistic value of the THR was used.
The procedure for disaggregation of the $6 \mathrm{~h}$ precipitation events consists of two steps [18]: the stratiform component is determined with the exponential curve and then the THR is determined.

The exponential function is fitted by the method of Nelder and Mead [25]. The condition that the curve does not have values higher than the total cumulative precipitation is introduced and the minimum cumulative precipitation values are identified. The fitted curve has to pass through these minimum values. The stratiform component below the curve is subtracted from the total precipitation and the rest represents the convective component.

After fitting the exponential curve, THR has to be identified. In original study, the THR was such precipitation rate when the 50 percent of cumulative precipitation was identified as of convective origin [17]. Here we used the condition proposed by Ruiz-Leo et al. [18]: sixty percent of total cumulative precipitation is represented by the contribution of convective component. Events with precipitation larger than THR are then assumed by the method to be predominantly of convective origin (hereafter referred to as above THR) and the events with lower precipitation than THR are assumed to be predominantly of stratiform origin (hereafter referred to as below THR).

2.4. Precipitation Characteristics. Two indices were selected for trend analysis: cumulative precipitation amount and number of events. The indices were evaluated for the precipitation events with intensities above the THR, the events with intensities below the THR, and for total precipitation. The indices were calculated for May-September (ALL, all available 
data) and for summer (JJA, June-July-August) separately for the western region and the eastern region.

2.5. Trend Assessment. Trends were evaluated by using two approaches: the parametric least-squares regression method, for example, [26] and the nonparametric Sen estimator [27]. We have used the Mann-Kendall test for evaluation of the statistical significance of trends obtained by Sen estimator $[28,29]$. We have applied the significance levels $p=0.1$ and $p=0.2$ because precipitation has usually lower statistical significance of trends than other climate variables [6].

2.6. Correlation with Air Temperature. The reported slope of scaling is different for different temperatures: CC scaling was observed for temperatures below 12 Celsius degrees and super CC for temperatures above 12 Celsius degrees [13]. For high temperatures, the negative scaling was observed and explained by the reduced moisture availability [19]. Other important influence is the aforementioned type of precipitation (convective versus stratiform). The super CC scaling have been explained by coexistence of the two types of precipitation at higher temperatures [12]. Therefore, it is preferable, when possible, to study separately the convective and stratiform precipitation.

Here, we used the modified temperature binning method (TB) $[19,20]$. The method is based on comparison of $6 \mathrm{~h}$ intensities with daily mean temperature (Tmean). We evaluated all $6 \mathrm{~h}$ events above $0.1 \mathrm{~mm}$ (instead of looking at maximum daily intensities only) in order to allow for assessment of scaling relations for precipitation of both convective and stratiform origin. The precipitation is aggregated into 15 bins based on corresponding temperature such that the number of observations in each bin is approximately equal. The mean temperature for a given bin is then calculated. Then, the $n$th percentile of each bin is estimated and the scaling slope is identified by fitting a least-squares linear regression to the precipitation amount.

\section{Results and Discussion}

3.1. Threshold Precipitation Rate. The threshold precipitation rate (THR) has been obtained for all available data in given year (ALL, mid-May to mid-September) and for summer (JJA, Jun-August) separately for the western region and for the eastern region for 1962-2011. Then, the 10-year moving average was calculated. To be able to compare the obtained results with results of previous studies [6], we evaluated the 1966-2006 and 1982-2006 separately. The obtained THRs are presented in Table 2. The lowest value of THR was obtained for the JJA Western region in 1982-2006. The highest value of THR was obtained for ALL in the same region. In general, the obtained THRs are lower for JJA than for ALL as there is higher occurrence of the events above the THR.

Regarding the temporal changes in THR, the values are lower for 1982-2006 than for 1966-2006 in the western region for both JJA data and ALL data. Consequently, the increasing occurrence of events above THR is likely for the region.
TABLE 2: THR in mm/6 h for 1982-2006 and 1966-2006 for both regions and ALL and JJA data.

\begin{tabular}{lcc}
\hline Region/season & $1982-2006$ & $1966-2006$ \\
\hline Western/ALL & 19.38 & 19.76 \\
Western/JJA & 16.69 & 17.40 \\
Eastern/ALL & 17.88 & 17.13 \\
Eastern/JJA & 17.06 & 16.84 \\
\hline
\end{tabular}

TABLE 3: Percentage of events above and below THR 1982-2006 and 1966-1981 for both regions and ALL and JJA data.

\begin{tabular}{lcccc}
\hline & \multicolumn{2}{c}{$1982-2006$} & \multicolumn{2}{c}{$1966-2006$} \\
& $\uparrow$ THR & $\downarrow$ THR & $\uparrow$ THR & $\downarrow$ THR \\
\hline \multicolumn{5}{c}{ Volume } \\
\hline Western/ALL & 13.22 & 86.78 & 13.24 & 86.76 \\
Western/JJA & 18.55 & 81.45 & 17.82 & 82.18 \\
Eastern/ALL & 20.05 & 79.95 & 19.91 & 80.09 \\
Eastern/JJA & 22.83 & 77.17 & 21.66 & 78.34 \\
\hline & 1.47 & 98.53 & 1.45 & 98.55 \\
\hline Western/ALL & 2.35 & 97.65 & 2.20 & 97.80 \\
Western/JJA & 2.70 & 97.30 & 2.69 & 97.31 \\
Eastern/ALL & 3.23 & 96.77 & 3.04 & 96.96 \\
Eastern/JJA & \multicolumn{5}{c}{}
\end{tabular}

3.2. Characteristics of Precipitation above and below THR. The percentages of numbers of $6 \mathrm{~h}$ events and amount of precipitation are presented in Table 3 . The portion of precipitation amount of events above THR is higher for JJA than for ALL in both regions. Similarly, the number of events is higher in JJA. The two evaluated time periods differ insignificantly. The obtained results corresponds well with previous findings for territory of the Czech Republic regarding the precipitation amount [6]. Interestingly, the average volume of an event above THR is higher for the western region.

The boxplots of precipitation amounts (Figure 2) shows the precipitation amounts for ALL and JJA events in the western region $(a, b)$ and in eastern region $(c, d)$ averaged for one station. The number of events is presented in Figure 3.

3.3. Trends in Precipitation. The trends in characteristics of precipitation and their statistical significance are presented in Table 4 (number of events) and in Table 5 (precipitation amounts). In general, the results of linear regression (LR) and Sen's estimator (Sen) are very similar. The positive trends of number of events above THR were detected in the western region for both 1982-2006 and 1982-2006. The negative trend was detected for events below THR for 1966-2006 in the region.

On the other hand, the trends of number of events above the THR are not statistically significant in the eastern region. The negative trend of number of total events is statistically significant in the eastern region.

Regarding the analysis of trends in precipitation amounts, we evaluated the sum of the exceedances above THR (denoted $\uparrow \uparrow$ THR in Table 5), the precipitation amount of events above the THR, and the precipitation amount of events 


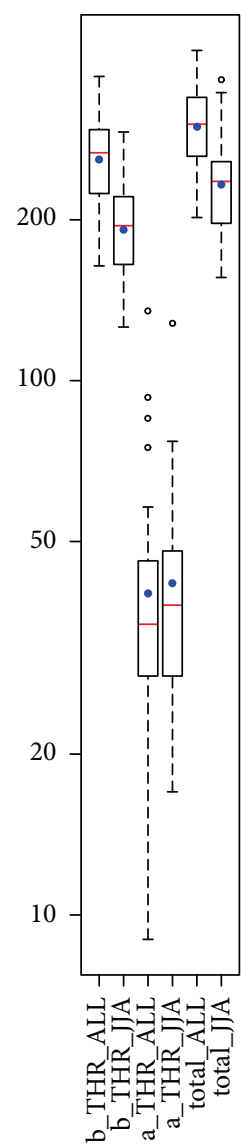

(a)

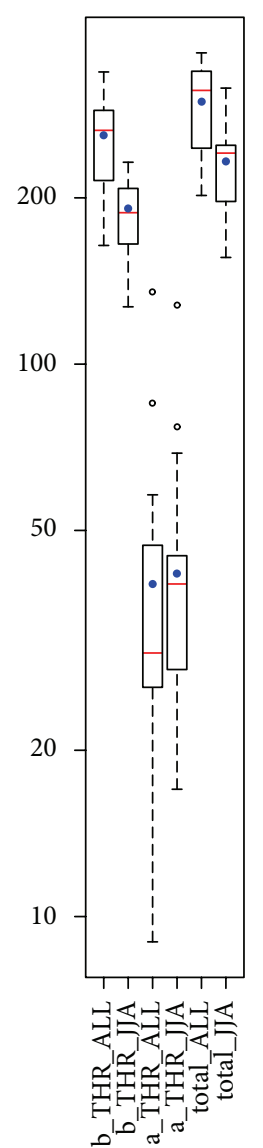

(b)

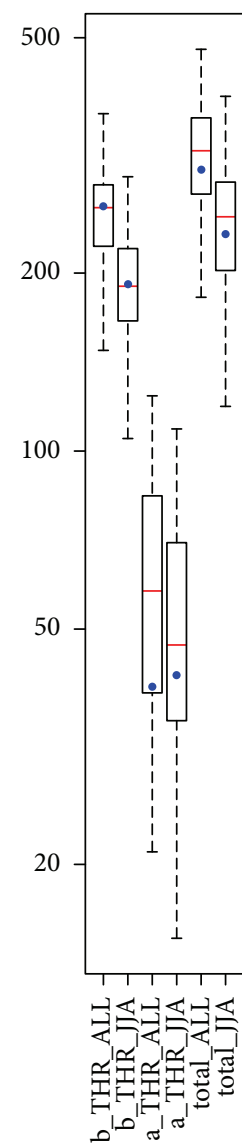

(c)

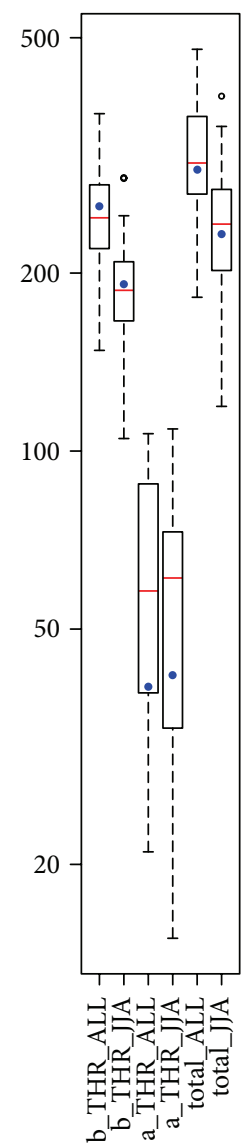

(d)

FIGURE 2: Boxplots for annual precipitation amounts averaged for one station: b_THR_ALL: events below THR for ALL, b_THR_JJA: events below THR for JJA, a_THR_ ALL: events above THR for ALL, total_ALL: total amount for ALL, and total_JJA: total for JJA; (a) western 1966-2006, (b) western 1982-2006, (c) eastern 1966-2006, and (d) eastern 1982-2006.

TABLE 4: Number of events above and below THR 1982-2006 and 1966-2006 for both regions and ALL and JJA data. 0.1 (0.2) denotes trend significant at $0.1(0.2)$ level.

\begin{tabular}{|c|c|c|c|c|c|c|}
\hline & \multicolumn{3}{|c|}{ 1982-2006 } & \multicolumn{3}{|c|}{ 1966-2006 } \\
\hline & $\uparrow \mathrm{THR}$ & $\downarrow$ THR & Total & $\uparrow \mathrm{THR}$ & $\downarrow$ THR & Total \\
\hline & \multicolumn{6}{|c|}{ LR } \\
\hline Western/ALL & $\uparrow 0.1$ & $\uparrow$ & $\uparrow$ & $\uparrow 0.1$ & $\downarrow 0.1$ & $\downarrow$ \\
\hline Western/JJA & $\uparrow 0.2$ & $\uparrow$ & $\uparrow$ & $\uparrow 0.2$ & $\downarrow 0.2$ & $\downarrow$ \\
\hline Eastern/ALL & $\uparrow$ & $\downarrow$ & $\downarrow$ & $\downarrow$ & $\downarrow$ & $\downarrow 0.1$ \\
\hline \multirow[t]{2}{*}{ Eastern/JJA } & $\uparrow$ & $\downarrow$ & $\downarrow$ & $\downarrow$ & $\downarrow$ & $\downarrow 0.1$ \\
\hline & \multicolumn{6}{|c|}{ Sen } \\
\hline Western/ALL & $\uparrow 0.1$ & $\uparrow$ & $\uparrow$ & $\uparrow 0.2$ & $\downarrow 0.1$ & $\downarrow$ \\
\hline Western/JJA & $\uparrow 0.2$ & $\uparrow$ & $\uparrow$ & $\uparrow 0.2$ & $\downarrow 0.2$ & $\downarrow$ \\
\hline Eastern/ALL & $\uparrow$ & $\downarrow$ & $\downarrow$ & $\downarrow$ & $\downarrow$ & $\downarrow 0.1$ \\
\hline Eastern/JJA & $\uparrow$ & $\downarrow$ & $\downarrow$ & $\downarrow$ & $\downarrow$ & $\downarrow 0.1$ \\
\hline
\end{tabular}

below the THR. For the western region, the positive trends for events above the THR are statistically significant in ALL data for 1982-2006 and 1966-2006.
For the eastern region, the trends in precipitation amount of events above the THR are not statistically significant. There are positive statistically significant trends for precipitation amount of events below the THR and total events in ALL data for 1966-2006. In contrast, the opposite trend was identified for JJA (Table 5).

The identified statistically significant positive trends of events above the THR in the western region are in line with previous findings $[5,6]$.

3.4. Scaling with Temperature. In order to assess the influence of storm type on scaling of precipitation intensity with temperature, we have used the modified TB method on the $6 \mathrm{~h}$ precipitation events (categorized in previous section) and daily temperature. The results on estimated scaling slopes in percent per Celsius degree are presented in Table 6. The slopes for all events are in range from $1.1 \%$ (75th percentile for the western region) to $9.7 \%$ per degree of Celsius (95th percentile for the eastern region). The scaling slopes are steeper for higher percentiles.

The hypothesis that the scaling of total precipitation with air temperature is a result of shift from stratiform to a convective regime [12] is applicable on our results. For high 


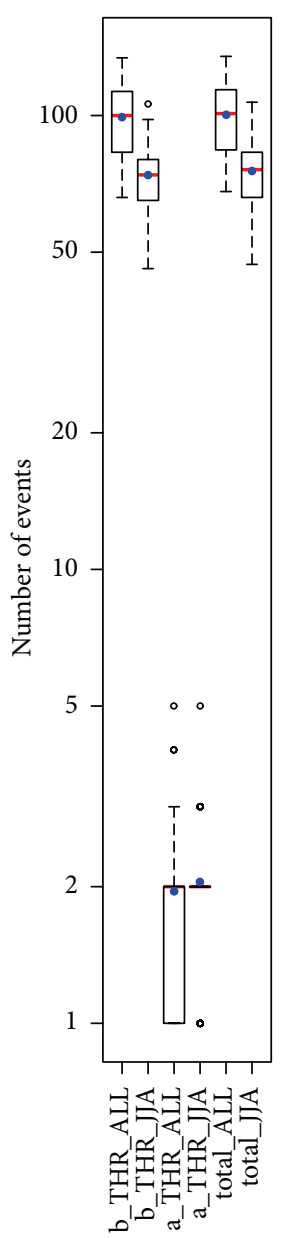

(a)

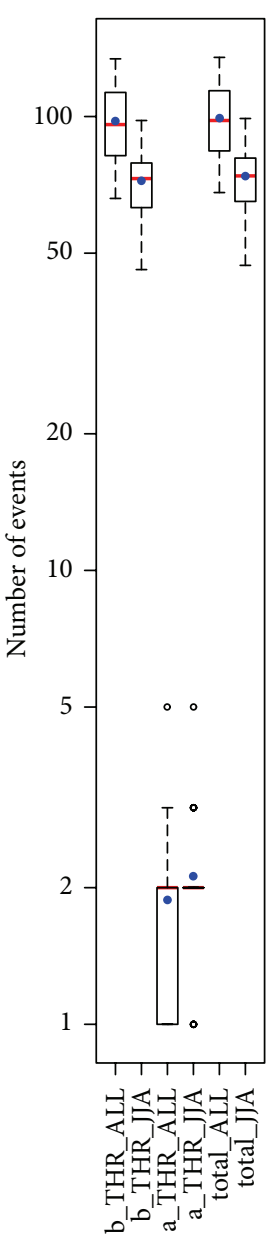

(b)

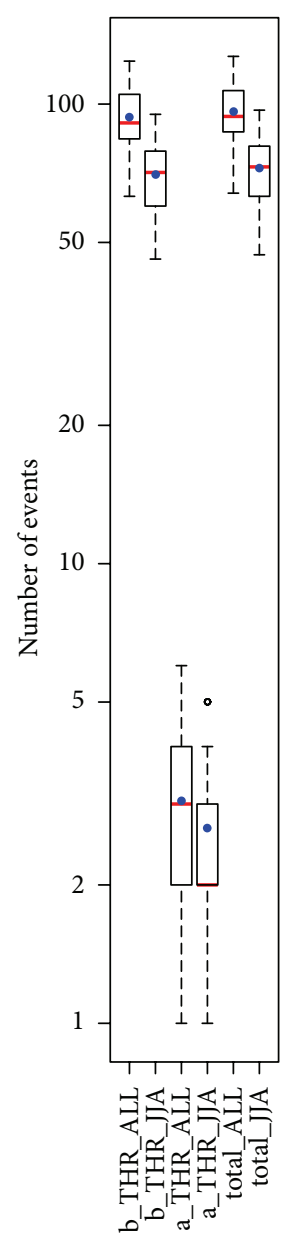

(c)

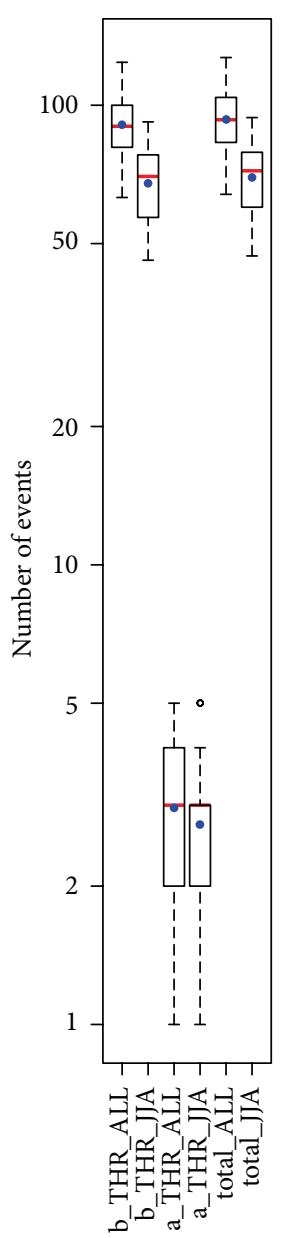

(d)

FIGURE 3: Boxplots for annual number of events averaged for one station: b_THR_ALL: events below THR for ALL, b_THR_JJA: events below THR for JJA, a_THR_ ALL; events above THR for ALL, total_ALL: total amount for ALL, and total_JJA: total for JJA; (a) western 1966-2006, (b) western 1982-2006, (c) eastern 1966-2006, and (d) eastern 1982-2006.

percentiles, the obtained scaling slopes of total events are steeper than these obtained separately for events above the THR and for events below the THR (Table 6). At lower temperatures, the events below THR are more abundant and at higher temperatures the events above THR prevail [14].

The negative scaling is usually observed for higher temperatures [13]. It was described as a consequence of declining moisture availability [19]. To analyze the change of scaling, we applied the locally weighted scatterplot smoothing (LOESS, [30]). The results are presented in Figure 4. In general, the scaling slopes are negative for higher Tmean.

\section{Conclusions}

We identified the threshold precipitation rate (THR) for the $6 \mathrm{~h}$ events in the Czech Republic for 1966-2006. The methodology we use is based on the assumption that precipitation of stratiform origin follows the exponential function. We analyzed the characteristics of events above THR (prevailing convective component) and below THR (prevailing stratiform component). We analyzed trends in these characteristics using the least-squares regression and Sen's estimator. Finally, we evaluated correlation of precipitation intensities with daily mean temperature.

Answering the questions postulated in the introduction, we summarize our main findings as follows.

(1) In general, the obtained THRs are lower for JJA than for ALL, as there is higher occurrence of convective events. THRs obtained for the western region are lower for 1982-2006 than for 1966-2006. This indicates an increasing occurrence of convective events in the region. On the other hand, the THR for JJA in the eastern region is higher for 1982-2006 than for 19662006. Therefore, the occurrence of events above THR has probably decreased.

(2) Trends in precipitation above THR are increasing and statistically significant for precipitation amounts and the number of events for ALL in western region. These increasing trends were identified for both evaluated time periods. The increasing trends in precipitation are also statistically significant for most JJA data. 
TABLE 5: Precipitation amounts above and below THR 1982-2006 and 1966-2006 for both regions and ALL and JJA data. 0.1 (0.2) denotes trend significant at $0.1(0.2)$ level.

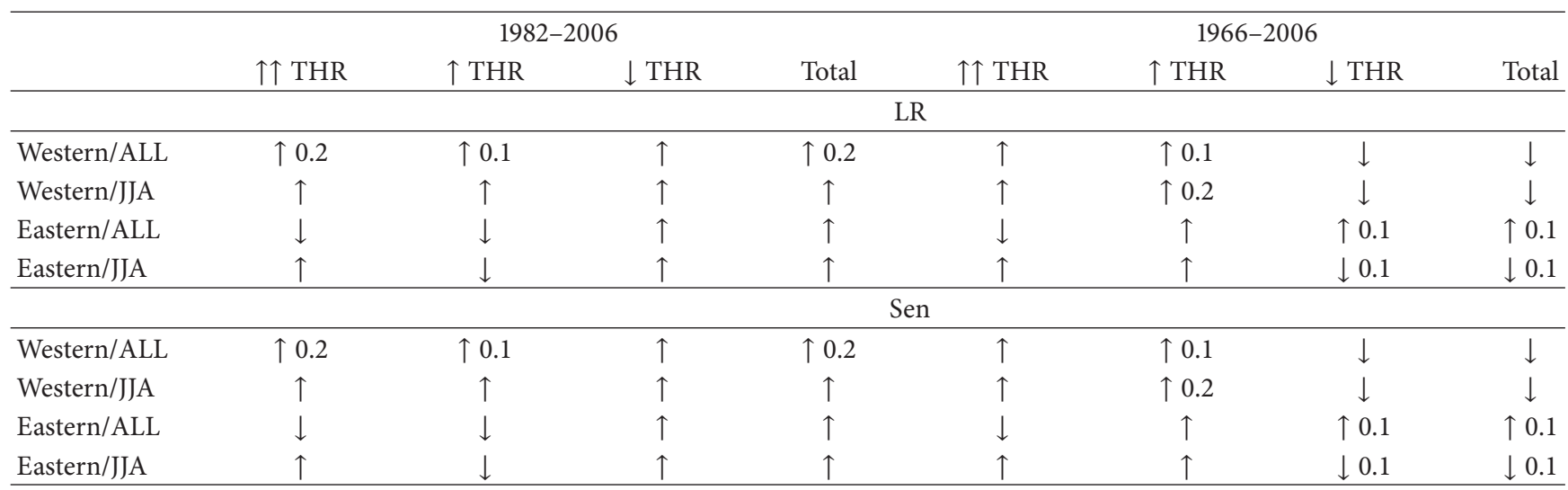

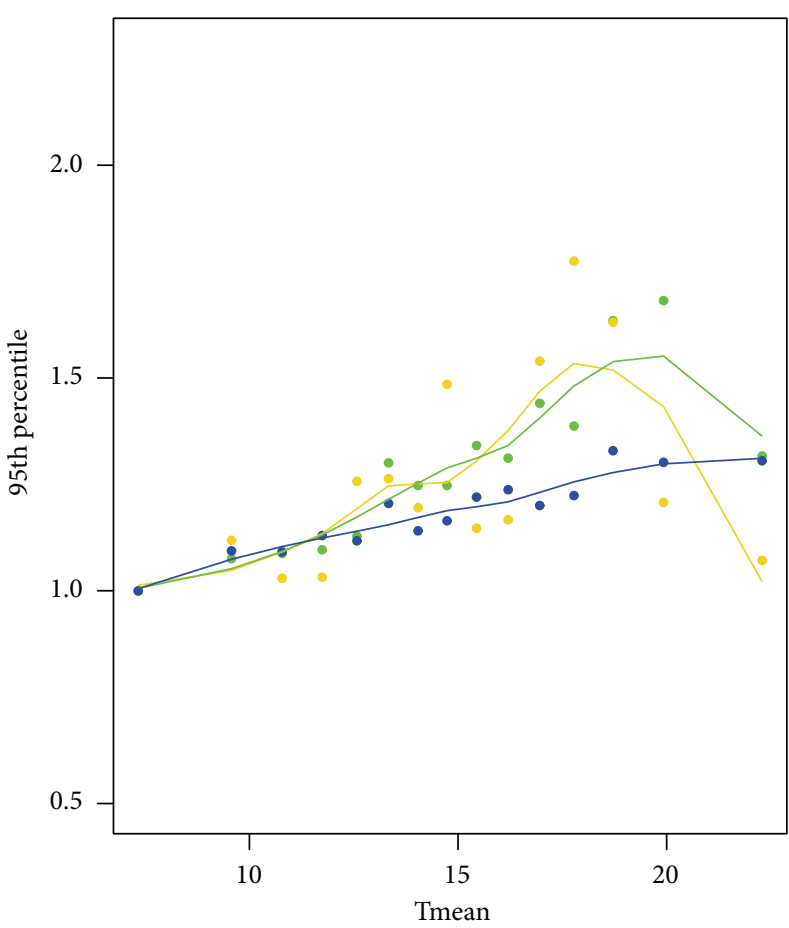

(a)

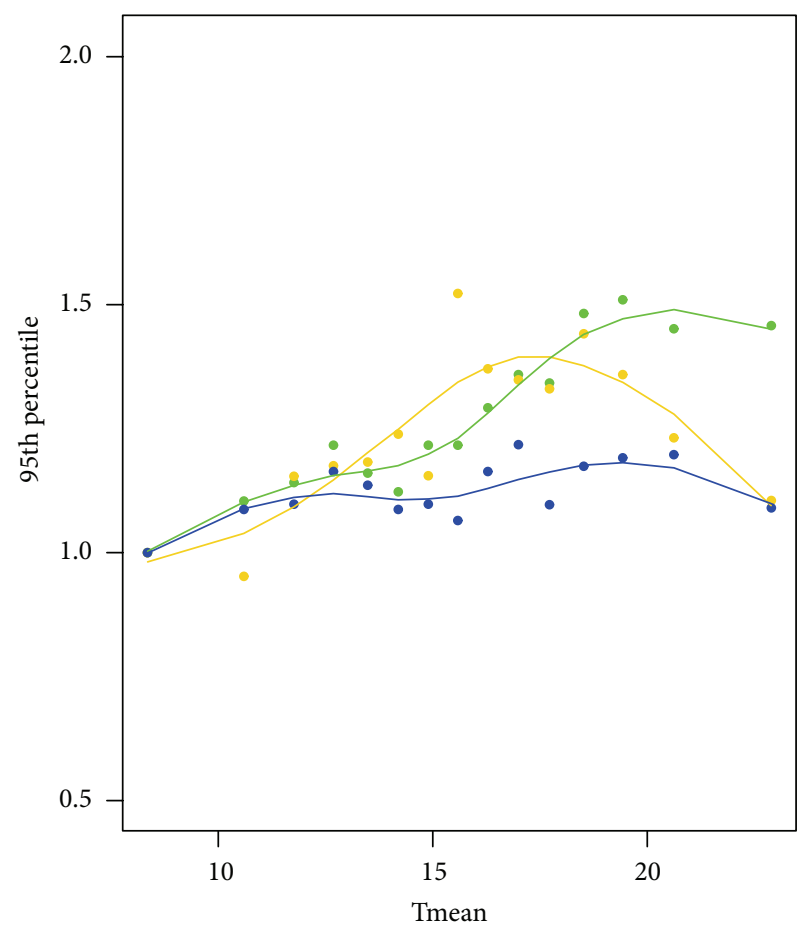

(b)

FIGURE 4: The LOESS-estimated scaling between the Tmean and precipitation of events below the THR (blue) and above the THR (yellow) and total (green) for the western region (a) and for the eastern region (b). The values on $y$-axis were divided by the first value.

TABLE 6: Scaling slopes. W/E denotes western/eastern region. Numbers $(75,90$, and 95$)$ denote the respective percentile.

\begin{tabular}{lllllll}
\hline Type & W75 & W90 & W95 & E75 & E90 & E95 \\
\hline Total & 1.40 & 5.20 & 6.70 & 3.30 & 5.00 & 9.70 \\
$\uparrow$ THR & 2.00 & 2.20 & 2.30 & 1.20 & 1.90 & 2.90 \\
$\downarrow$ THR & 0.80 & 1.90 & 2.60 & 1.10 & 1.30 & 1.10 \\
\hline
\end{tabular}

(3) The identified scaling slopes of the $6 \mathrm{~h}$ precipitation intensities versus the air temperature are flatter than the slopes of the $1 \mathrm{~h}$ daily precipitation extremes identified by previous studies. The scaling slope is steeper with higher intensity percentile for both regions. For high percentiles, the obtained scaling slopes of total precipitation are steeper than these obtained separately for events above the THR and for events below the THR.

(4) The scaling for total rain events is steeper than for the events above the THR and the events below the THR. It is a result of mixing of the two storm types. At higher temperature the events above THR prevail and vice versa.

To sum up, the hypothesis on different climate conditions in the western region and in the eastern region of the Czech 
Republic and the findings on increasing trends in extreme precipitation in the western region agree with our results. The methodology used here can be easily implemented for any precipitation series with a $6 \mathrm{~h}$ or finer time resolution. Further efforts should be focused on implementing the methodology in analysis of climate modeling outputs to increase the understanding of climate change impact on the future precipitation extremes.

\section{Competing Interests}

The authors declare that they have no competing interests regarding the publication of this paper.

\section{Acknowledgments}

This study was partly supported by project Erosion Runoff Increased Risk of the Residents and the Water Quality Exposure in the Context of the Expected Climate Change (VG 20122015092, the Ministry of the Interior of the Czech Republic) and by Grant 422200/1312/3157 IGA FZP CZU, Evaluation of Climate Change Impact on High Flows in Catchments. The authors acknowledge the E-OBS dataset from the EU-FP6 project ENSEMBLES (http://ensembles-eu.metoffice.com/) and the data providers in the ECA\&D project (http://www .ecad.eu/).

\section{References}

[1] J. H. Christensen and O. B. Christensen, "Severe summertime flooding in Europe," Nature, vol. 421, no. 6925, pp. 805-806, 2003.

[2] H. Madsen, D. Lawrence, M. Lang, M. Martinkova, and T. R. Kjeldsen, "Review of trend analysis and climate change projections of extreme precipitation and floods in Europe," Journal of Hydrology, vol. 519, pp. 3634-3650, 2014.

[3] Z. W. Kundzewicz, Changes in Flood Risk in Europe, Special Publication no. 10, IAHS Press, Wallingford, UK, 2012.

[4] P. Frich, L. V. Alexander, P. Della-Marta et al., "Observed coherent changes in climatic extremes during the second half of the twentieth century," Climate Research, vol. 19, no. 3, pp. 193-212, 2002.

[5] J. Kyselý and R. Beranová, "Climate-change effects on extreme precipitation in central Europe: uncertainties of scenarios based on regional climate models," Theoretical and Applied Climatology, vol. 95, no. 3-4, pp. 361-374, 2009.

[6] Z. Rulfová and J. Kyselý, "Trends of convective and stratiform precipitation in the Czech Republic, 1982-2010," Advances in Meteorology, vol. 2014, Article ID 647938, 11 pages, 2014.

[7] J. S. Pal, F. Giorgi, and X. Bi, "Consistency of recent European summer precipitation trends and extremes with future regional climate projections," Geophysical Research Letters, vol. 31, no. 13, 2004.

[8] G. Lenderink and E. Van Meijgaard, "Increase in hourly precipitation extremes beyond expectations from temperature changes," Nature Geoscience, vol. 1, no. 8, pp. 511-514, 2008.

[9] M. A. Sunyer, Y. Hundecha, D. Lawrence et al., "Inter-comparison of statistical downscaling methods for projection of extreme precipitation in Europe," Hydrology and Earth System Sciences, vol. 19, no. 4, pp. 1827-1847, 2015.
[10] G. Lenderink and E. Van Meijgaard, "Linking increases in hourly precipitation extremes to atmospheric temperature and moisture changes," Environmental Research Letters, vol. 5, no. 2, Article ID 025208, 2010.

[11] G. Lenderink, H. Y. Mok, T. C. Lee, and G. J. Van Oldenborgh, "Scaling and trends of hourly precipitation extremes in two different climate zones-Hong Kong and the Netherlands," Hydrology and Earth System Sciences, vol. 15, no. 9, pp. 30333041, 2011.

[12] J. O. Haerter and P. Berg, "Unexpected rise in extreme precipitation caused by a shift in rain type?" Nature Geoscience, vol. 2, no. 6, pp. 372-373, 2009.

[13] S. Westra, H. J. Fowler, J. P. Evans et al., "Future changes to the intensity and frequency of short-duration extreme rainfall," Reviews of Geophysics, vol. 52, no. 3, 2014.

[14] P. Berg and J. O. Haerter, "Unexpected increase in precipitation intensity with temperature-a result of mixing of precipitation types?" Atmospheric Research, vol. 119, pp. 56-61, 2013.

[15] P. Molnar, S. Fatichi, L. Gaál, J. Szolgay, and P. Burlando, "Storm type effects on super clausius-clapeyron scaling of intense rainstorm properties with air temperature," Hydrology and Earth System Sciences, vol. 19, no. 4, pp. 1753-1766, 2015.

[16] Z. Rulfová and J. Kyselý, "Disaggregating convective and stratiform precipitation from station weather data," Atmospheric Research, vol. 134, pp. 100-115, 2013.

[17] A. Tremblay, "The stratiform and convective components of surface precipitation," Journal of the Atmospheric Sciences, vol. 62, no. 5, pp. 1513-1528, 2005.

[18] A. M. Ruiz-Leo, E. Hernández, S. Queralt, and G. Maqueda, "Convective and stratiform precipitation trends in the Spanish Mediterranean coast," Atmospheric Research, vol. 119, pp. 46-55, 2013.

[19] R. H. Jones, S. Westra, and A. Sharma, "Observed relationships between extreme sub-daily precipitation, surface temperature, and relative humidity," Geophysical Research Letters, vol. 37, no. 22, Article ID L22805, 2010.

[20] S. Blenkinsop, S. C. Chan, E. J. Kendon, N. M. Roberts, and H. J. Fowler, "Temperature influences on intense UK hourly precipitation and dependency on large-scale circulation," Environmental Research Letters, vol. 10, no. 5, Article ID 054021, 2015.

[21] J. Kyselý, L. Gaál, J. Picek, and M. Schindler, "Return periods of the August 2010 heavy precipitation in northern Bohemia (Czech Republic) in the present climate and under climate change," Journal of Water and Climate Change, vol. 4, no. 3, pp. 265-286, 2013.

[22] P. Willems, "Multidecadal oscillatory behaviour of rainfall extremes in Europe," Climatic Change, vol. 120, no. 4, pp. 931944, 2013.

[23] M. Hanel, A. Pavlásková, and J. Kyselý, "Trends in characteristics of sub-daily heavy precipitation and rainfall erosivity in the Czech Republic," International Journal of Climatology, vol. 36, no. 4, pp. 1833-1845, 2016.

[24] M. R. Haylock, N. Hofstra, A. M. G. Klein Tank, E. J. Klok, P. D. Jones, and M. New, "A European daily high-resolution gridded data set of surface temperature and precipitation for 19502006," Journal of Geophysical Research Atmospheres, vol. 113, no. 20, Article ID D20119, 2008.

[25] J. A. Nelder and R. Mead, "A simplex method for function minimization," The Computer Journal, vol. 7, no. 4, pp. 308-313, 1965.

[26] D. S. Wilks, Statistical Methods in the Atmospheric Sciences, vol. 100, Academic Press, 2011. 
[27] P. K. Sen, "Estimates of the regression coefficient based on Kendall's tau," Journal of the American Statistical Association, vol. 63, no. 324, pp. 1379-1389, 1968.

[28] H. B. Mann, "Nonparametric tests against trend," Econometrica, vol. 13, no. 3, pp. 245-259, 1945.

[29] M. G. Kendall, Rank Correlation Methods, 1948.

[30] W. S. Cleveland, "Robust locally weighted regression and smoothing scatterplots," Journal of the American Statistical Association, vol. 74, no. 368, pp. 829-836, 1979. 

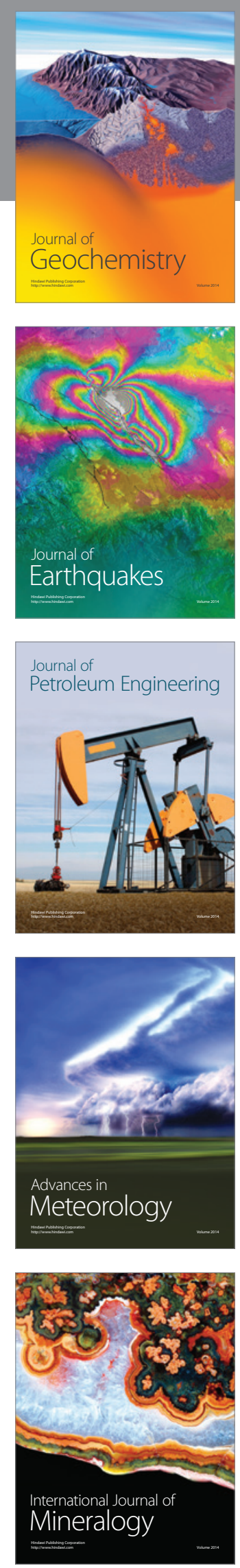
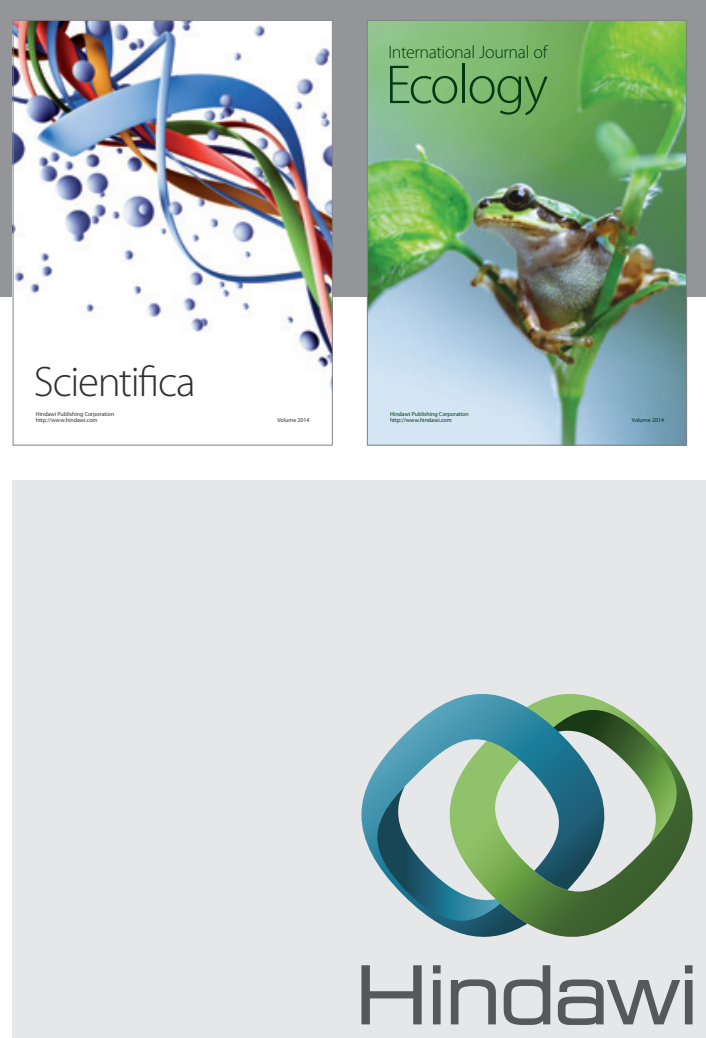

Submit your manuscripts at

http://www.hindawi.com
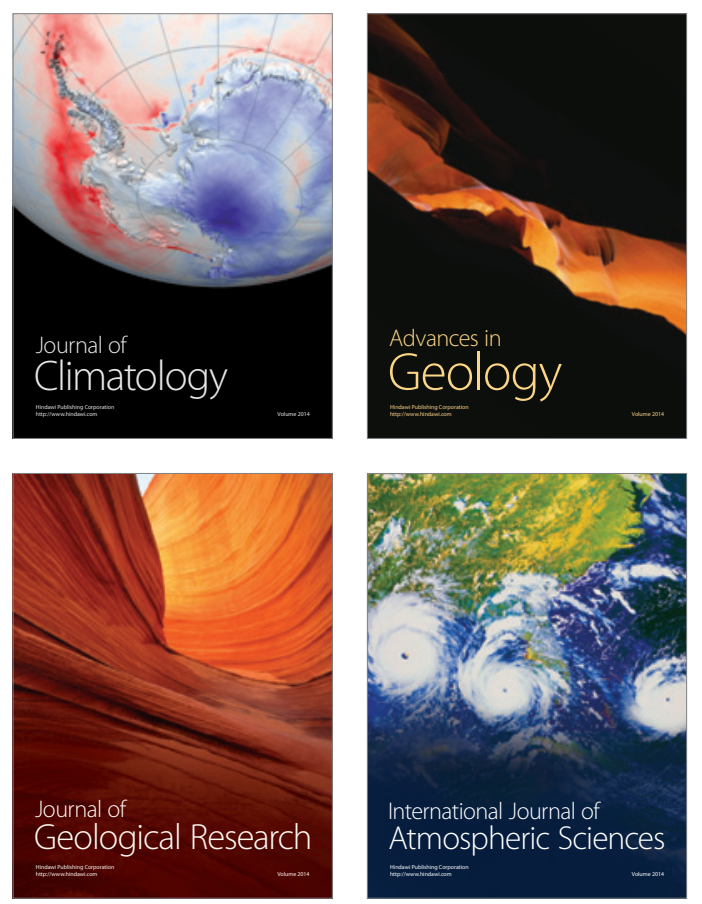

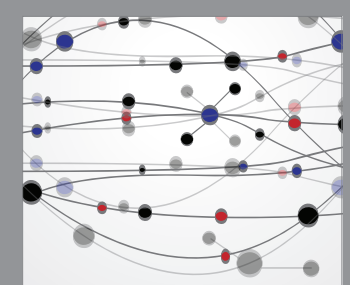

The Scientific

\section{World Journal}
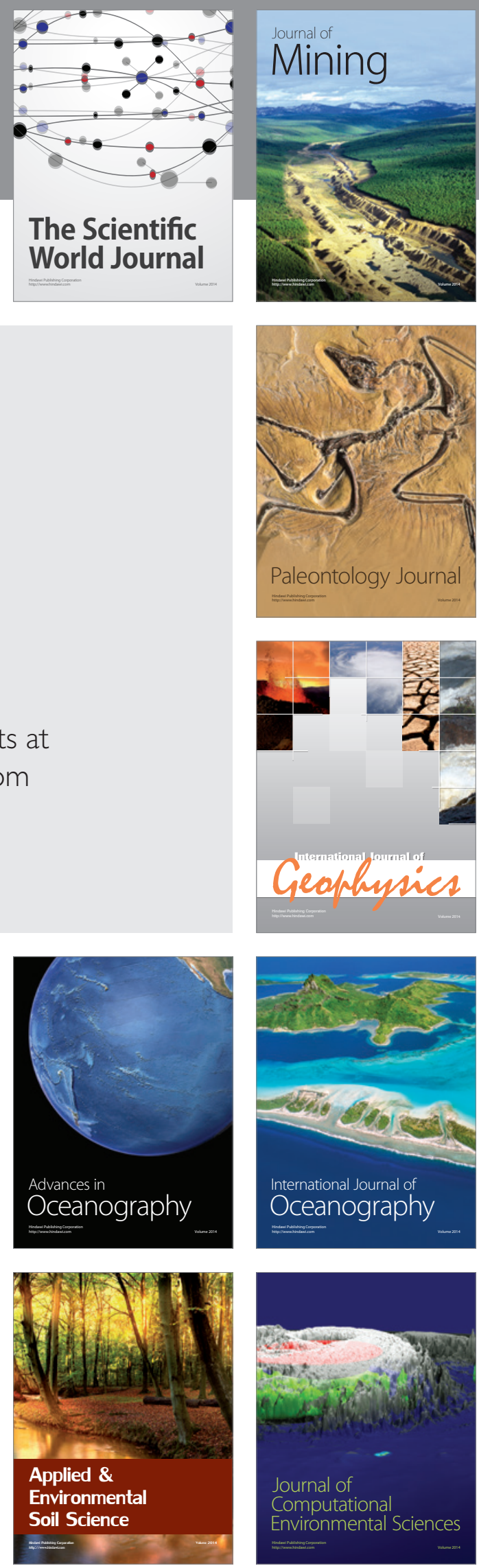